----مجلة علوم الرافدين، المجلد 27، العدد 4/ عدد خاص بالمؤتمر العلمي الثالث لعلوم الحياة، ص 388-401، 2018--
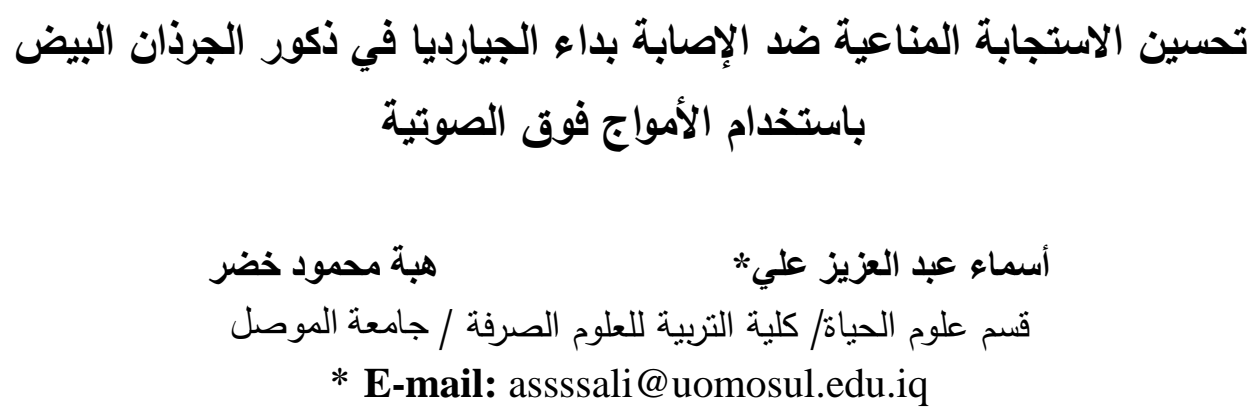

$$
\text { (أستلم 2018/6/20 ؛ قُبل 2018/ } 11 \text { الملخص }
$$

تتاولت الدراسـة الحاليـة تحديد تأثير الموجـات فوق الصـوتية، بوصفها محفزاً للمناعـة، ضــ الإصـابة بـداء الجيارديـا

Giardiasis المرضية في الجرذان المجرعة فموياً بأكياس الجيارديا لامبليا المعرضة ولفترات زمنية مختلفة، 60 ثانية، 150 ثانية، 210 ثانية

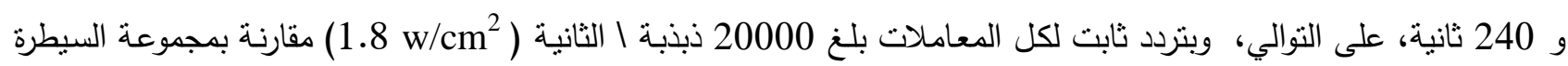
(الجرذان المجرعة فموياً بأكياس الجيارديا غير المعرضة للموجات فوق الصوتية) طيلة فترة التجربة، اعتماداً على معايير عديدة

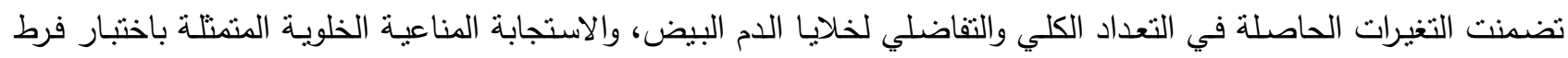

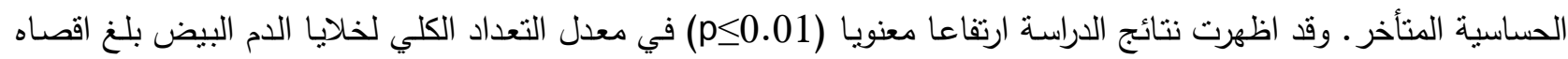

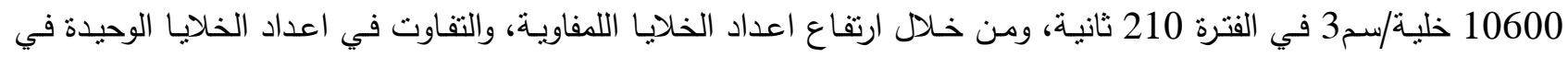
الحيوانات المعاملة، كما حصلت زيادة معنوية(p<0.01 ) في الاستجابة المناعية الخلوية متمنلة بارتفاع معدلات سمك وسادة القدم (الانتفاخ)، بلغ أقصاه 1.75 ملم في الفترة 240 ثانية بعد مرور 3 ساعات من الحقن، ورافقه أيضا زيادة في الحيوانات المعاملة مقارنة بمجموعة السيطرة (10.225 ملم).

الكلمات الدالة: Giardia lamblia، الامواج فوق الصوتية، الاستجابة المناعية.

\title{
Immune Response Improvement Against Giardiasis in Male Albino Rats by Using Ultrasound
}

\author{
Asmaa A. Aziz Ali \\ Hiba M. Khethr \\ Department of Biology/College of Education for Pure Sciences/University of Mosul
}

\begin{abstract}
The present study investigated the effect of the direct ultrasonic waves, as an immune stimulator, against infection with giardiasis caused by Giardia lamblia in Norwegian rats Rattus norvegicus. The pathological changes occurred in the rats administered orally with the cysts of $G$. lamblia, exposed to different durations of ultrasonic waves 60 seconds, 150s, 210s and 240s, respectively, with constant frequency 20.000 pulselsecond $\left(1.8 \mathrm{w} / \mathrm{cm}^{2}\right)$ were followed in comparison with the control group (rats administered orally with the cysts of G. lamblia, without exposure to the ultrasonic waves), along the experiments period, depending on many criteria, included the changes in the total and differential count of leukocytes (WBCs), and specific (cellular) immunity, represented by skin- delayed type hypersensitivity test. The results of the present study revealed a significant increase $(\mathrm{p} \leq 0.01)$ in the total count of leukocytes, the maximum count was 10600
\end{abstract}


cell $/ \mathrm{cm}^{3}$ at duration 210 s, expressed by increase in lymphocytes, variation in monocytes numbers in treated animals.A significant increase $(\mathrm{p} \leq 0.01)$ in the cellular immunity, represented by elevation in the rates of foot pad thickness (swelling), the maximum thickness was $1.75 \mathrm{~mm}$ at duration $240 \mathrm{~s}$ in treated animals, in comparison with control group $(0.225 \mathrm{~mm})$.

Keywords: Giardia lamblia, Ultrasonic waves, Immune stimulator

\section{المقدمة}

يعد طفيلي الجيارديا Giardia lamblia من الابتدائيات المعوية، التي تصيب الأمعاء الدقيقة للحيوانات الفقرية،

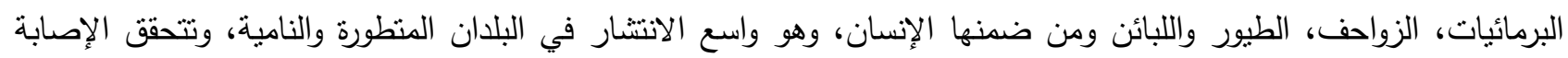

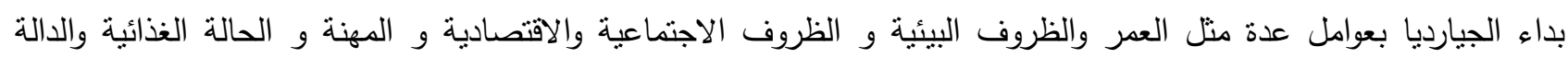
Aycan-Kaya et al., 2012; Kamda et al.,2012; Samn et ( تقضل المعتدلة) وحالة المضيف المناعية pH .(al., 2012;Omarova et al.2018

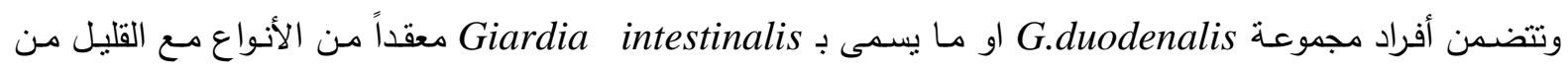

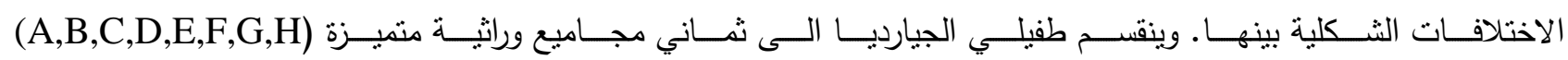
(Caccio and Ryan, 2008; Monis et al., 2009, Cotton et al., 2014;Turki et al.2015) تصيبان الانسان هما A و Buret, 2008). يشكل طفيلي الجيارديا المسبب الثائع للإسهال الثحمي Steatorrhea) ويؤدي معين الى حالات إمراضية ووفيات عالية (Carmena, 2010; Ringqvista et al., 2011) ويؤدي ايضاً الى تأخر النمو في الأطفال

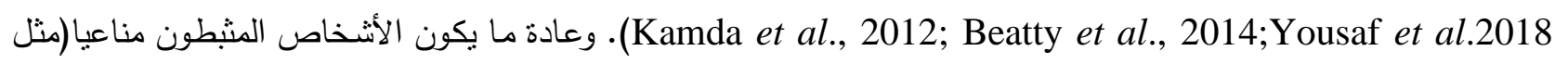

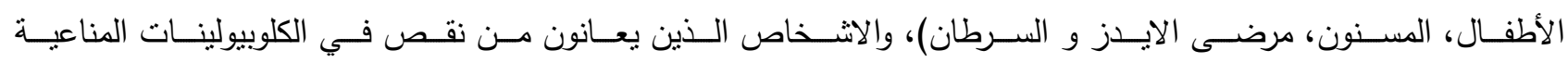

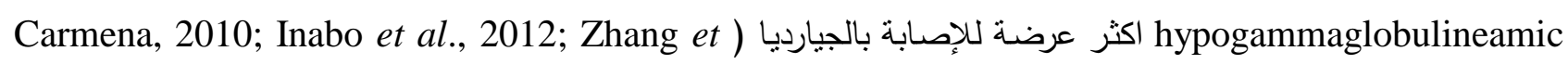
.$(a l ., 2016$

ولازالت ميكانيكية الإمراضية لهذا الطفيلي و استجابة المضيف للإصابة مبهمة، لكن الدراسات الحديثة تقترح بأن الأطوار المتغذية للطفيل، تعد عملية فسلجية مرضية متعددة العوامل تتضمن تحطيم الحافة الفرثاتية Brush Border للأمعاء والطبقة

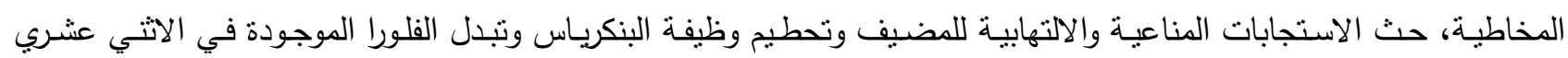

.(Beatty et al., 2014; Bhargava et al., 2014; Cotton et al.,2014; Gerbaba et al., 2014) و يعد هيدروكلوريد الكيناكرين العلاج المفضل لداء الجيارديا وكثيراً ما يحصل دوار وصداع وقياء بفعل هذا الدواء، وقد يؤدي احياناً الى ذهان سمي واعتلال دموي شرى والتهاب جلدي، نلون الجلد بالاصفر وتصبغ الاظفار باللون الازرق والأسود، لذلك تعد مشتقات Nitroimidazole التي تتضمن ( Ornidazole, Tinidazole, Metronidazole ) العلاج البديل وجميعها تثبط بناء الحامض النووي الراييوزي المنقوص الاوكسجين DNA، ولكن سجل عدد من التأثيرات الجانبية الحادة له مثل التهاب

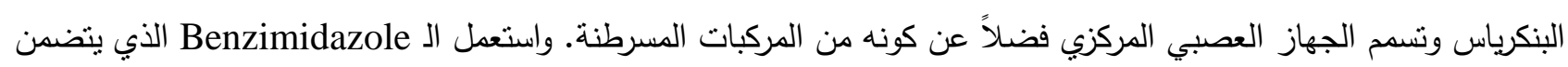

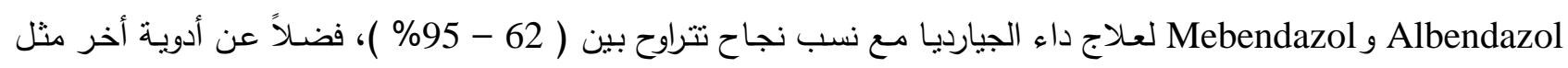
.(Carmena, 2010) Quinacrine, Furazolidone, Paromomycin Poorsaadat et al. واتجه الباحثون إلى ايجاد وسائل بديلة لمكافحة الجيارديا منها التبار الكهربائي، إذ هدف الباحثون (2004) إلى تحديد تأثير التيار الكهربائي المباشر Direct electricity current في تطهير الماء الجاري (ماء الحنفية) من طفيل G.lambi، وأظهرت النتائج الني توصل اليها Ahmad (2013) أن التيار الكهربائي ساعد على ثقليل اختزال مدة بقاء 
الطفيل في جسم المضيف وقلل من طرح الطور المتكيس في الجرذان النرويجية بمستوى معنوي عال، وتبين ان عدداً من سلالات

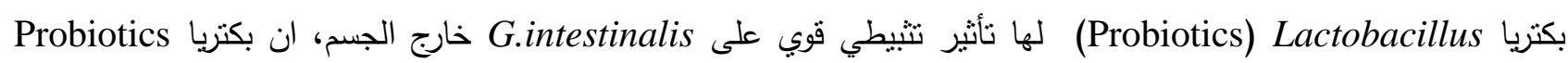

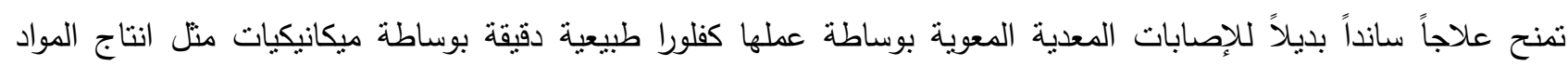
المضادة للمكروبات وتثبيط انتاج السموم وتثبيط دخول المكروبات إلى داخل الخلية وتحفيز الاستجابة المناعبة والمناعة الجهازية Simpson et al., 2009; Shukla et ) والمخاطية ضد داء الجيارديا في مختلف نماذج الحيوانات مثل (الكلاب و القوارض . (al., 2010

واتجه الباحثون في السنوات الأخيرة إلى تطبيق ثقنية الموجات فوق الصوتية ultrasonic waves كطريقة حرارية، غير اختراقية لاستئصال الأنسجة ولمعالجة الأمراض المختلفة التي تضم التليف تحت المخاطي Submucosal Fibroid (Cheung et al., 2012) Hepatic Cellular Carcinoma وسرطان الخلايا الكبدية (Wang et al., 2012) الغدي البروستاتي Prostate Adeno Carcinoma (NICE, 2012; Liu et al.,2013) وتليف الرحم Uterine Fibrosis، سرطان البنكرياس Pancreatic Carcinoma وسرطان الثي Breast Carcinoma وسرطان الغدد اللمفاوية المنتشر Lymph Node Metastasis والعضلية Sarcoma، سرطان الكلى Renal Carcinoma وأورام الغدد الصم العصبية Neuroendocrine Tumors (Al- Bataineh et al., 2012; NICE, 2012) البكتيرية (Monisn et al., 2009) والأمراض الطفيلية منل داء الأكياس العدرية Cai et al., 2013; Hydatid disease) وأكياس الجيارديا خارج الجسم (Al-Sabi et al., 2011). liu et al., 2013; Zhang et al.,2013) نظراً للأعراض الجانبية الكثيرة التي نسبيها الأدوية المستعملة في علاج الجيارديا، لذا هدفت الدراسة الحالية الى استعمال

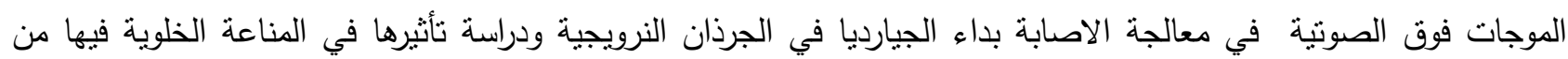

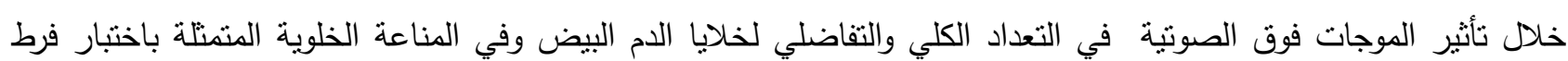
الحساسية المتأخر في الحيوانات المعاملة مقارنة بحيوانات السبطرة.

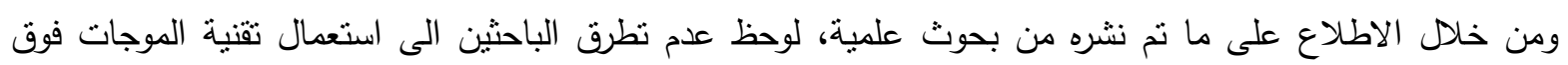

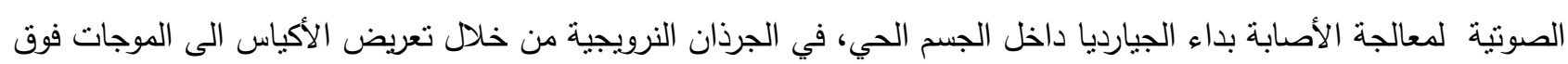

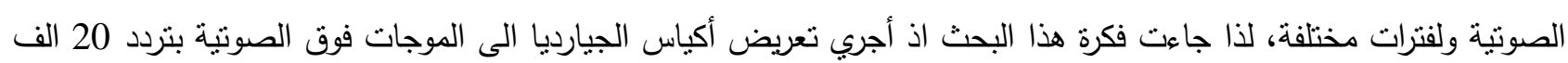

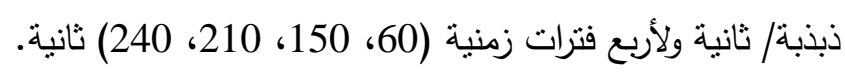

\section{المواد وطرائق العمل}

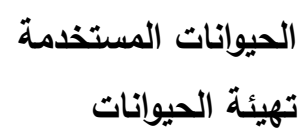

تم الحصول على الجرذان النرويجية نوع Rattus norvegicus بعمر (6- 6- 7) أثنهر من بيت الحيوانات التابع لكلية الطب البيطري في جامعة الموصل، وتم تكثير هذه الحيوانات في غرفة تربية الحيوانات في كلية التربية/ قسم علوم الحياة في جامعة الموصل. وجرى فحص براز الحيوانات بالطريقة المباشرة للتأكد من خلوها من الطفيليات المعوية. كثرت هذه الحيوان فئان وعزلت الذكور منها عن الإناث في أقفاص لوحدها وبواقع 4 ذكور لكل قفص، إذ استخدمت في التجارب المختلفة بعمر (3- 4)

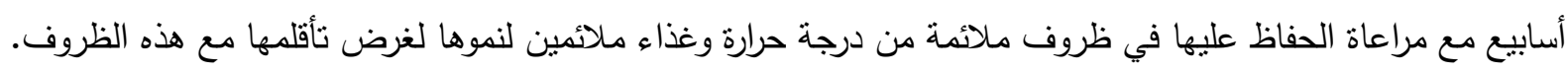


جمع وعزل عينات الطقيليات

جُمعت العينات من مختبر الطفيليات في مستشفى السلام في الموصل للفترة من تشرين الثاني 2012 ولغاية تشرين الأول 2013 بعد فحص الغائط الوارد إلى المختبر المذكور فحصاً مباشرا باستعمال المحلول الملحي الفسلجي بتركيز 0.9\% ومحلول

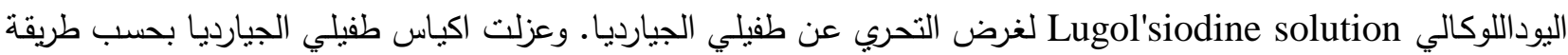
Shnawa (1995) مع عدد من التحويرات التي اتبعتها: Bingham et al. (1979) تجريع الحيوانات المختبرية جرعت الجرذان المختبرية عن طريق الفم orally في هذه الدراسة بمعلق الأكياس في المحلول الملحي الفسلجي الحاوي

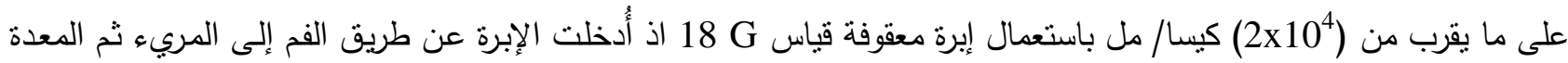
ودفع السائل الحاوي على الأكياس إلى داخل المعدة مباشرة (Roberts-Thomson et al.,1976). تصميم التجرية ودع قسمت ذكور الجرذان الى خمس مجاميع بواقع أربعة حيوانات لكل مجموعة، وعدت المجموعة الاولى كمجوعة السيطرة فيما مثلت المجاميع الأربع الباقية المجاميع التجريبية. والمجموعة الاولى هي مجموعة السيطرة: المجرعة بأكياس طفيلي الجيارديا وغير المعاملة بالموجات فوق الصونية، وهي

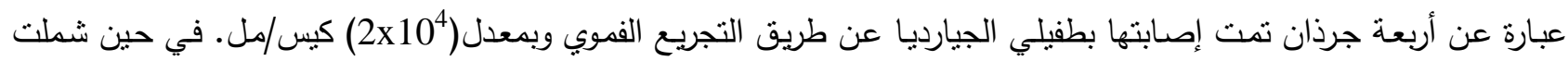

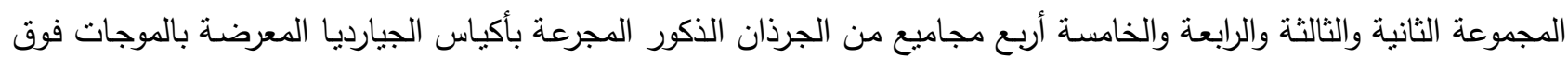
الصوتية عند التردد 20 ألف ذبذبة /ثانية ولفترات زمنية مختلفة (60، 150، 210، 240) ثانية، على التوالي، وبواقع أربعة جرذان لكل تجربة ودرست فيها المعايير المستعملة في الدراسة الحالية. الجهاز المستخدم في الاراسة الحالية استخدم في الدراسة الحالية جهاز الموجات فوق الصوتية Ultrasonic انكليزي المنشأ، في قسم علوم الحياة، كلية العلوم، جامعة الموصل، الذي وفرته شركة Omniinternational كما مبين في الثنل (1).

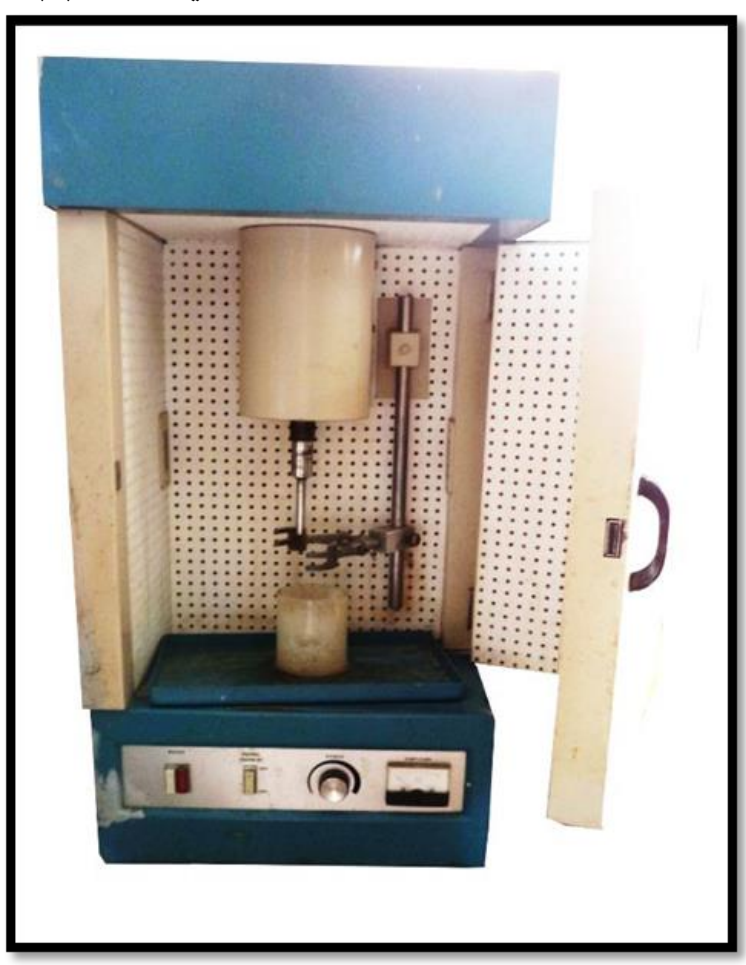




\section{Ultrasonic الثكل 1: جهاز الموجات فوق الصوتية}

المعاييز المختارة في الاراسة

جمع الام

بعد معاملة الجرذان وعند انتهاء الفترات المذكورة انفا، اذ خدرت الجرذان باستعمال ثثائي اثيل الايثر Diethylether وسحب الدم من محجر العين باستعمال أنبوبة شعرية وفق طريقة (1980) Waynforth، وجمع الدم في أنابيب بسعة 5 مل حاوية على مانع التخثر EDTA) Ethylene Diamine Tetra Acetic Acid) لغرض حساب العدد الكلي والتفريقي لخلايا الدم البيض.

الاستجابة المناعية الخلوية (اختبار فرط الحساسية المتأخر)

تم تحضير المستضد وفقاً لطريقة (1982) Craft and Nelson. اذ حُطمت أو فُجرت الأكياس للحصول على مسنضد

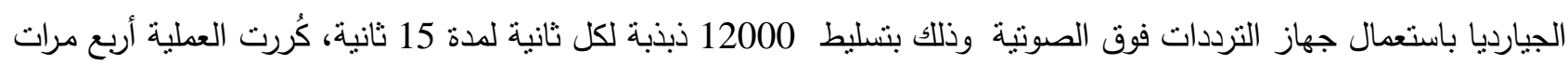

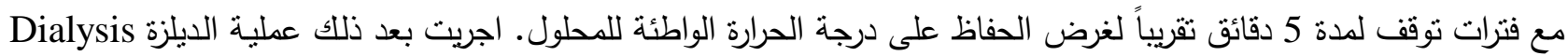
لمدة 48 ساعة ضد فئرات الماء المقطر. تقدير كمية البروتين

قدرت كمية البروتين الكلي وفق طريقة (1973) Schacterle and Pollack المحورة في بعض المواد البايولوجية، قيست شدة الامتصاصية عند طول موجي 650 نانومتر باستعمال جهاز المطياف الضوئي ( Spectrophotometersingle (beam نوع (CAMBRLDJE.1011) الذي جهزته شركة Cecil Instrument limited ـ تم تحديد تركيز البروتين الكلي في العينة باستعمال المنحنى القياسي للبروتين الذي حضر بأخذ نراكيز مختلفة تراوحت بين(1000-0) مايكروغرام/مل من ألبومين

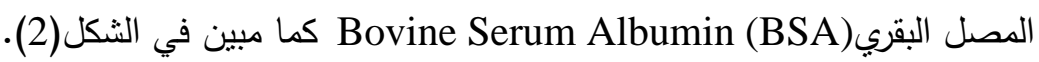

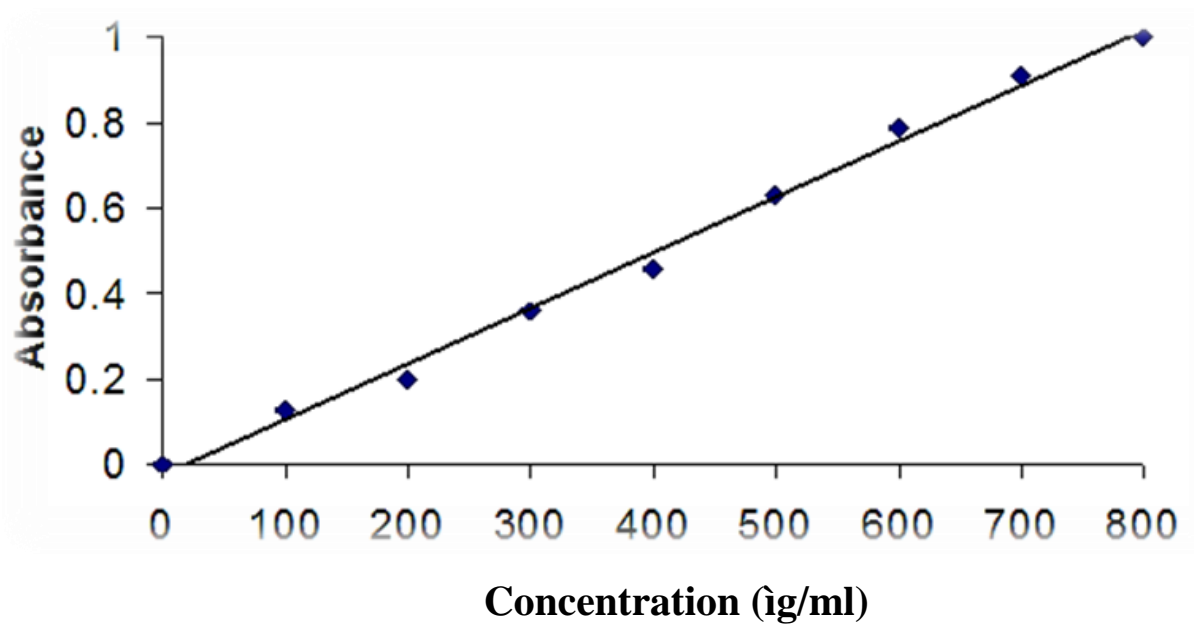

الثكل 2 : المنحنى القياسي لتقدير كمية البروتين

حقن المستضد اثُبعت طريقة (1978) Ali Khan لقياس فرط الحساسية المتأخر ، إذ حُقتت وسادة القدم اليمنى للجرذ بمستضد أكياس طفيل الجيارديا بتركيز 174 مايكروغرام بعد تعقيم منطقة الحقن بالكحول ( 70\%) وباستعمال محقنة طبية بحجم 1 مل ذات إبرة قياس25G، أما القدم الأخرى فحقنت بالحجم نفسه من دارئ الفوسفات الملحي المعقم. تم قياس سمك القدم باستعمال 
القدمة Vernier بعد 3، 24 ، 48 ساعة من الحقن لحساب الفرق بين القراءتين لوسادتي القدم اليمنى واليسرى بوصفها مقياساً لفرط الحساسية المتأخر .

\section{التحليل الاحصائي}

حلت بيانات الصفات المختلفة بحسب طريقة التصميم العشوائي الكامل Complete Random Design (CRD) (Gomez and Gomez, 1983) Duncan's Multiple Range Test

الإحصائي الجاهز Statistical Analysis System V.9 (SAS)

\section{النتائج والمناقشة}

Total count of leukocytes التعداد الكلي لخلايا الدم البيض

ويظهر (الجدول 1) التعداد الكلي لخلايا الدم البيض في مجموعة حيوانات السيطرة والمجاميع المعاملة بالموجات فوق الصوتية لفترات زمنية مختلفة، وقد لوحظ ارتفاع عدد خلايا الدم البيض في الجرذان المعاملة مقارنة مع مجموعة السيطرة إذ فيط

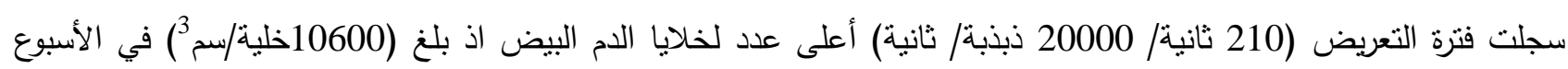

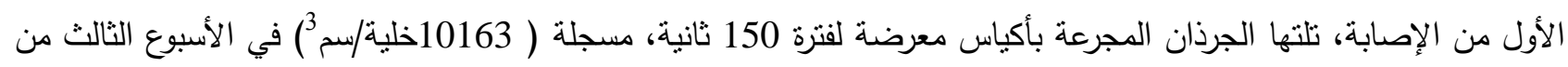

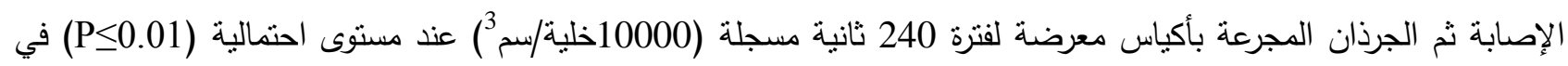

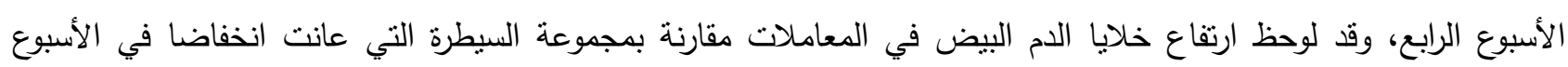

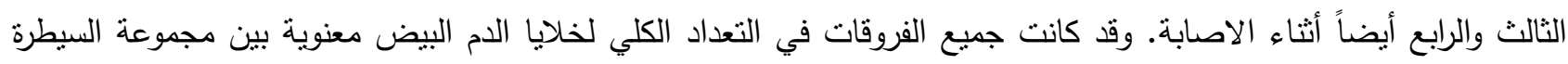
والمجاميع المعاملة عند مستوى احتمالية (p<0.01).

الجدول 1: يبين التغيرات الحاصلة في معدلات التعداد الكلي لخلايا الدم البيض في الجرذان المعاملة مقارنة بمجموعة السيطرة

\begin{tabular}{|c|c|c|c|c|c|}
\hline \multicolumn{4}{|c|}{ فترة التعريض ( ثانية ) } & \multirow{2}{*}{ السيطرة } & \multirow{3}{*}{ الاسابيع } \\
\hline 240 & 210 & 150 & 60 & & \\
\hline *المعلد ألانحراف & *المعدل土 ألانحراف & 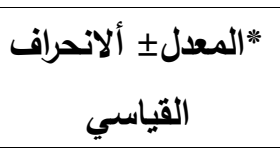 & 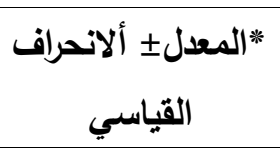 & 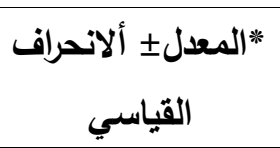 & \\
\hline $\begin{array}{c}8400 \pm 2033.0 \\
a-c\end{array}$ & $\begin{array}{c}10600 \pm 3813.1 \\
\mathrm{a}\end{array}$ & $\begin{array}{c}8050 \pm 1369.9 \\
\text { a-c }\end{array}$ & $\begin{array}{c}8000 \pm 1689.18 \\
\text { a-c }\end{array}$ & $\begin{array}{c}4250 \pm 491.596 \\
\mathrm{~d}\end{array}$ & الأول \\
\hline $\begin{array}{c}9400 \pm 1883.2 \\
\mathrm{a}-\mathrm{c}\end{array}$ & $\begin{array}{c}9175 \pm 3284.68 \\
a-c\end{array}$ & $\begin{array}{c}8100 \pm 2171.02 \\
\mathrm{a}-\mathrm{c}\end{array}$ & $\begin{array}{c}8575 \pm 1456.88 \\
\text { a-c }\end{array}$ & $\begin{array}{c}8013 \pm 3766.60 \\
\text { a-c }\end{array}$ & الثاني \\
\hline $\begin{array}{c}9750 \pm 1112.0 \\
\mathrm{a}-\mathrm{c}\end{array}$ & $\begin{array}{c}8125 \pm 2473.02 \\
a-c\end{array}$ & $\begin{array}{c}10163 \pm 1898.8 \\
\mathrm{a}\end{array}$ & $\begin{array}{c}7063 \pm 1931.05 \\
\text { a-d }\end{array}$ & $\begin{array}{c}6200 \pm 730.296 \\
\text { b-d }\end{array}$ & الثالث \\
\hline $\begin{array}{c}10000 \pm 2127.9 \\
\mathrm{a}\end{array}$ & $\begin{array}{c}6250 \pm 191.48 \\
a-c\end{array}$ & $\begin{array}{c}7650 \pm 2259.05 \\
\text { a-d }\end{array}$ & $\begin{array}{c}7525 \pm 2418.85 \\
\text { a-d }\end{array}$ & $\begin{array}{c}5713 \pm 647.269 \\
\mathrm{c}-\mathrm{d}\end{array}$ & الرابع \\
\hline
\end{tabular}

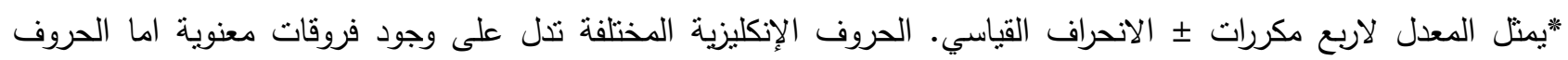
الإنكليزية المتثابهة والمشتركة فتدل على عدم وجود فروقات معنوية بحسب اختبار دنكن عند مستوى احتمالية (P<0.01). ويمكن أن تعزى الزيادة في التعداد الكلي لخلايا الام البيض إلى كون الموجات فوق الصوتية تعمل كمنشط غير نوعي أو عام للخلايا المسهمة في المناعة، إذ إنه يحفز انقسام الخلايا داخل الجسم وخارجه، ولاسيما هجرة البلاعم والخلايا المتعادلة وانقسامها. 
وقد اتفقت النتائج الحالية مع ما توصل إليه كل من Al-Dabbag and Rahemo (2010) إذ لاحظا زيادة في التعداد الكلي لخلايا الدم البيض نتيجة إحداث الإصابة في الجرذان النرويجية بأكياس الجيارديا المشععة بأثعة كاما لمدة ساعتين و 24 ساعة،

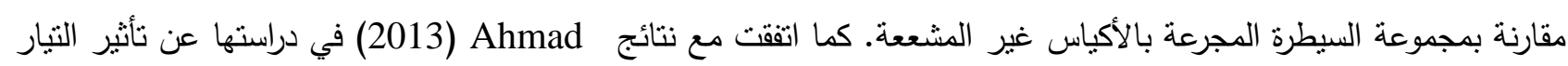
الكهربائي المباثر في الاستجابة المناعية للجرذان النرويجية المجرعة بأكياس الجيارديا مقارنة بمجاميع حيوانات السيطرة والسالبة. وأظهرت نتائج البحث التي أجريت على الجرذان المجرعة بأكياس الجيارديا غير المعرضة للموجات فوق الصوتية (السيطرة)

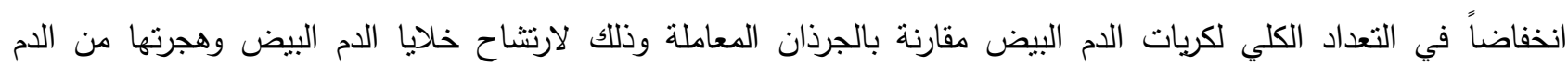
ووصولها الى مواقع الطفيلي (Cotton et al., 2014)، وقد بين الباحثون أن الارنتشاح المتزايد للخلايا اللمفاوية داخل البريتون مرتبط بداء الجيارديا (Faubert, 2000). وأوضحت دراسة (1991) . Vinayak et al أن الطور الحاد للإصابة بطفيلي CD8 Cytotoxic T cell Guodenalis الطلائية والصفيحة ألأصيلة. ومما تجدر الإثارة إليه أن هذه الزيادة في الارتشاح قد سجلت في الحيوانات الكفوءة مناعياً، وكذلك في الحيوانات عديمة الصعترية المصابة بالجيارديا أيضاً (Scott et al., 2004).

التعداد التفاضلي لخلايا الام البيض Differential count of leukocytes يتضح من (الجدول 2) التعداد التفاضلي لخلايا الدم البيض، إذ لوحظ انخفاض أعداد الخلايا العدلة neutrophils في

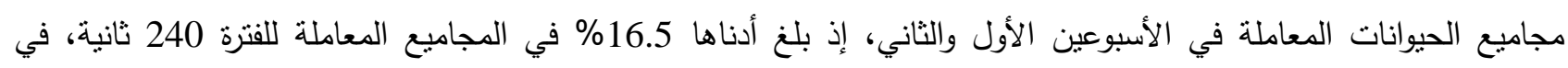

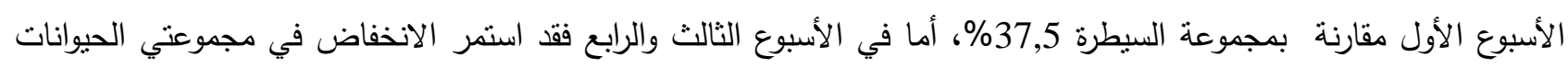

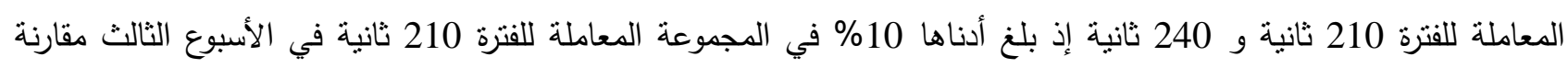
بمجموعة السيطرة 27.75\%. أما المجموعة المعاملة للفترة 60 ثانية فقد سجلت ارتفاعا في الخلايا العدلة في الأسبوعين الثالث

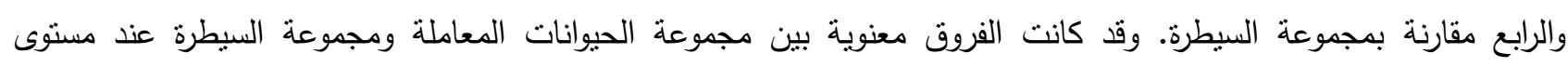

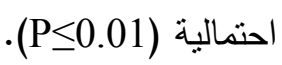

ويعزى انخفاض الخلايا العدلة في الحيوانات المعاملة الى تأثير الموجات فوق الصوتية في تحفيز انقسام الخلايا البلعمية والخلايا المتعادلة وهجرتها إلى مواقع الإصابة، وهذه النتيجة ممانلة لدراسات أخرى استعمل الباحثون فيها التيار الكهربائي كمؤثز في الاستجابة المناعية (Song et al., 2007; Cinar et al., 2009). كما يبين (الجدول 2) أعداد خلايا الدم البيض الحمضية في مجاميع الجرذان المعاملة بالموجات فوق الصوتية مقارنة

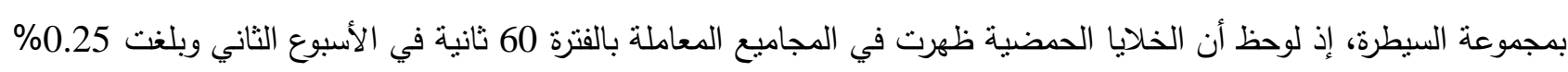

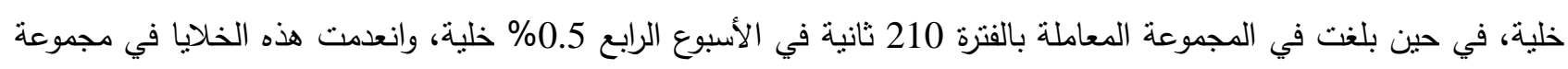
السيطرة والمجاميع المعاملة الأخر وكانت الفروق غير معنوية بين المجاميع المعاملة ومجموعة السيطرة عند مستوى احتمالية

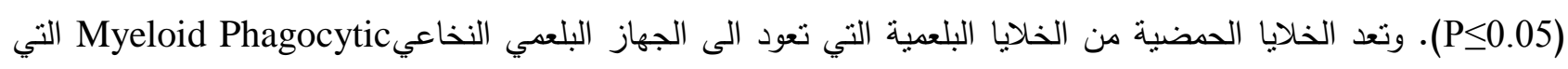

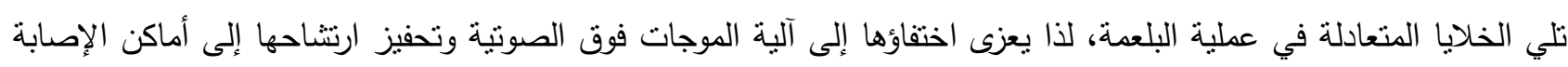
(Male et al., 2007) الصوتية، إذ لوحظ انعدام هذه الخلايا في كل المجاميع المعاملة ومجموعة السبطرة .

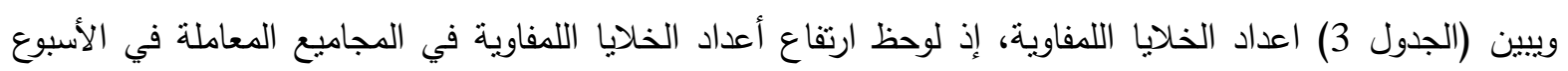

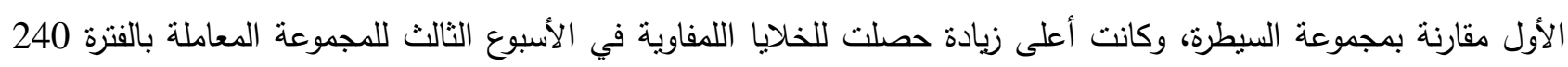

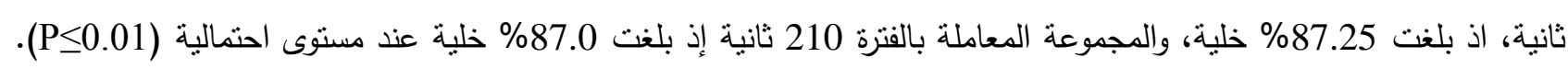
ثم انخفضت أعداد الخلايا اللمفاوية في المجاميع المعاملة في الأسبوع الثاني والثالث ولكن بقيت أنية أعلى مما في السيطرة التي 


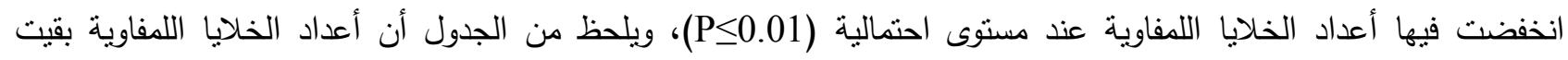
مرتفعة في المجاميع المعاملة مقارنة بمجموعة السيطرة طيلة فترة الاسابيع الاربعة وكانت الفروق معنوية بين المجاميع المعاملة عند مستوى احتمالية (P<0.01) ومجموعة السيطرة.

الجدول 2: يبين التغيرات الحاصلة في معدلات التعداد التفاضلي لخلايا الدم البيض الحبيبية (العدلة والحمضية والقعدة)

في الجرذان المعاملة مقارنة بمجموعة السيطرة

\begin{tabular}{|c|c|c|c|c|c|c|}
\hline \multicolumn{4}{|c|}{ فترة التعريض ( ثانية ) } & \multirow{2}{*}{ السيطرة } & \multirow{3}{*}{$\begin{array}{l}\overline{3} \\
3 \\
3\end{array}$} & \multirow{3}{*}{ الخلية } \\
\hline 240 & 210 & 150 & 60 & & & \\
\hline "المعدل ألانحراف & *المعدل ألانحراف & *المعدل ألانحراف & *المعدل ألانحراف & * المعدلد ألانحراف & & \\
\hline $\begin{array}{c}16.5 \pm 9.25 \\
\text { e-d }\end{array}$ & $\begin{array}{c}23.75 \pm 4.32 \\
\text { b-e }\end{array}$ & $\begin{array}{c}21.25 \pm 7.417 \\
\text { b-e }\end{array}$ & $\begin{array}{c}21.25 \pm 2.5 \\
\text { b-e }\end{array}$ & $\begin{array}{c}37,5 \pm 16.583 \\
\text { a-c }\end{array}$ & 离 & \\
\hline $\begin{array}{c}13.419 .25 \pm \\
\text { e-d }\end{array}$ & $\begin{array}{c}25.0 \pm 9.38 \\
b-e\end{array}$ & $\begin{array}{c}28,25 \pm 18.09 \\
\text { b-e }\end{array}$ & $\begin{array}{c}27.25 \pm 14.15 \\
\text { b-e }\end{array}$ & $\begin{array}{c}33.5 \pm 13.17 \\
\text { a-d }\end{array}$ & 牙 & Z \\
\hline $\begin{array}{c}12.0 \pm 1.414 \\
\mathrm{e}\end{array}$ & $\begin{array}{c}10.0 \pm 5.477 \\
\mathrm{e}\end{array}$ & $\begin{array}{c}38.5 \pm 10.954 \\
\text { a-c }\end{array}$ & $\begin{array}{c}32.5 \pm 9.255 \\
\text { a-d }\end{array}$ & $\begin{array}{c}27.75 \pm 8.693 \\
\text { b-e }\end{array}$ & 矛 & E. \\
\hline $\begin{array}{c}18.5 \pm 5.259 \\
\text { e-d }\end{array}$ & $\begin{array}{c}16.25 \pm 8.539 \\
\text { e-d }\end{array}$ & $\begin{array}{c}20.25 \pm 7.13 \\
\text { c-e }\end{array}$ & $\begin{array}{c}45.5 \pm 11.618 \\
\mathrm{a}\end{array}$ & $\begin{array}{c}38.75 \pm 17.61 \\
a-b\end{array}$ & $\overline{\frac{3}{2}}$ & \\
\hline $\begin{array}{r}0.00 \pm 0 \\
\text { B }\end{array}$ & $\begin{array}{ll}0 & 0.00 \pm \\
& b\end{array}$ & $\begin{array}{r}0.00 \pm 0 \\
b\end{array}$ & $\begin{array}{r}0.00 \pm 0 \\
\text { B }\end{array}$ & $\begin{array}{c}0.00 \pm 0 \\
\text { B }\end{array}$ & 离 & \\
\hline $\begin{array}{r}0.00 \pm 0 \\
\mathrm{~B}\end{array}$ & $\begin{array}{r}0.00 \pm 0 \\
b\end{array}$ & $\begin{array}{r}0.00 \pm 0 \\
b\end{array}$ & $\begin{array}{r}0.25 \pm 0.5 \\
a-b\end{array}$ & $\begin{array}{r}0.00 \pm 0 \\
\text { B }\end{array}$ & $\sqrt{3}$ & Tr \\
\hline $\begin{array}{r}0.00 \pm 0 \\
\text { B }\end{array}$ & $\begin{array}{r}0.00 \pm 0 \\
b\end{array}$ & $\begin{array}{c}0.00 \pm 0 \\
\mathrm{~b}\end{array}$ & $\begin{array}{r}0.00 \pm 0 \\
\text { B }\end{array}$ & $\begin{array}{r}0.00 \pm 0 \\
b\end{array}$ & 弐 & te \\
\hline $\begin{array}{r}0.00 \pm 0 \\
B\end{array}$ & $\begin{array}{r}0,5 \pm 1 \\
\text { a }\end{array}$ & $\begin{array}{c}0.00 \pm 0 \\
\mathrm{~b}\end{array}$ & $\begin{array}{r}0.00 \pm 0 \\
\text { B }\end{array}$ & $\begin{array}{r}0.00 \pm 0 \\
b\end{array}$ & $\frac{\overline{3}}{2}$ & \\
\hline $\begin{array}{r}0.00 \pm 0 \\
\mathrm{~A}\end{array}$ & $\begin{array}{r}0.00 \pm 0 \\
\mathrm{a}\end{array}$ & $\begin{array}{r}0.00 \pm 0 \\
\mathrm{a}\end{array}$ & $\begin{array}{r}0.00 \pm 0 \\
\mathrm{~A}\end{array}$ & $\begin{array}{r}0.00 \pm 0 \\
\mathrm{~A}\end{array}$ & 弯 & \\
\hline $\begin{array}{r}0.00 \pm 0 \\
\mathrm{~A}\end{array}$ & $\begin{array}{r}0.00 \pm 0 \\
\mathrm{a}\end{array}$ & $\begin{array}{r}0.00 \pm 0 \\
\mathrm{a}\end{array}$ & $\begin{array}{r}0.00 \pm 0 \\
\mathrm{~A}\end{array}$ & $\begin{array}{r}0.00 \pm 0 \\
\mathrm{~A}\end{array}$ & $\sqrt[\overline{7}]{3}$ & 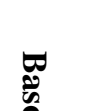 \\
\hline $\begin{array}{r}0.00 \pm 0 \\
\mathrm{~A}\end{array}$ & $\begin{array}{r}0.00 \pm 0 \\
\mathrm{a}\end{array}$ & $\begin{array}{r}0.00 \pm 0 \\
\mathrm{a}\end{array}$ & $\begin{array}{r}0.00 \pm 0 \\
\mathrm{~A}\end{array}$ & $\begin{array}{r}0.00 \pm 0 \\
\mathrm{~A}\end{array}$ & 牙 & E. \\
\hline $\begin{array}{r}0.00 \pm 0 \\
\mathrm{~A}\end{array}$ & $\begin{array}{r}0.00 \pm 0 \\
\mathrm{a}\end{array}$ & $\begin{array}{r}0.00 \pm 0 \\
\mathrm{a}\end{array}$ & $\begin{array}{r}0.00 \pm 0 \\
\mathrm{~A}\end{array}$ & $\begin{array}{r}0.00 \pm 0 \\
\mathrm{~A}\end{array}$ & $\overline{\frac{3}{2}}$ & \\
\hline
\end{tabular}




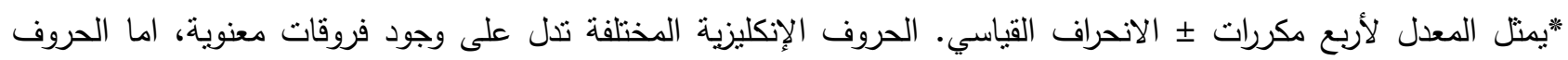

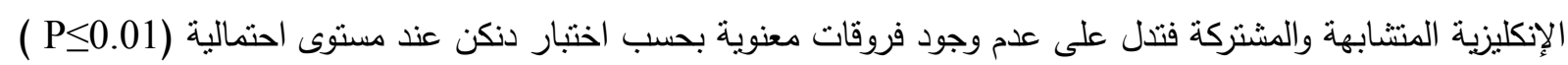

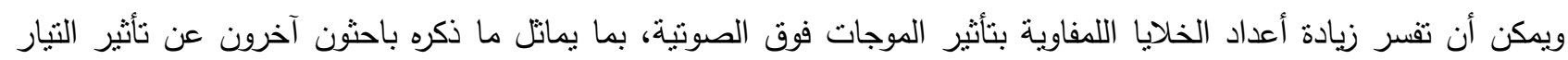

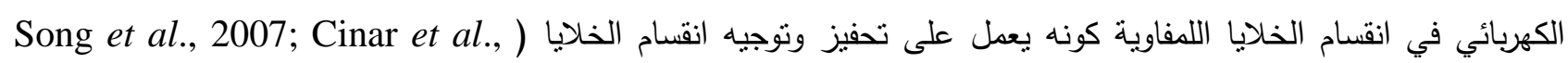
2009)، وقد جاءت هذه النتيجة مطابقة ايضا مع دراسات أخرى نتاولت نأثير التيار الكهربائي على أعداد الخلايا اللمفاوية، في

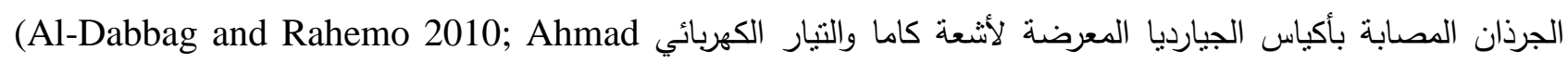
(2013. أما انخفاض أعداد الخلايا اللمفاوية في مجاميع السيطرة فيمكن أن يفسر بهجرة الخلايا اللمفاوية وانتقالها إلى مواقع

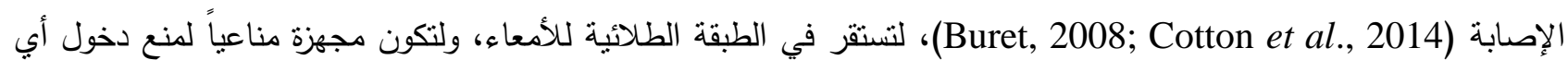

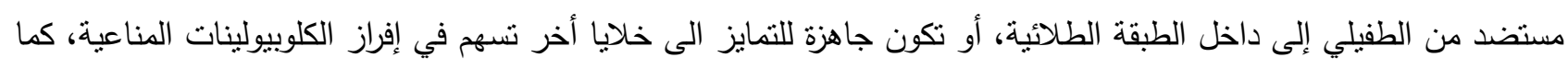

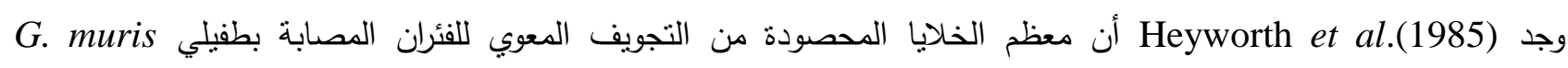
كانت خلايا لمفاوية مع عدد ضئيل من البلاعم الكبيرة. وعندما شخصت الخلايا بوساطة صبغة التألق المناعي Immune Fluorescent Staining

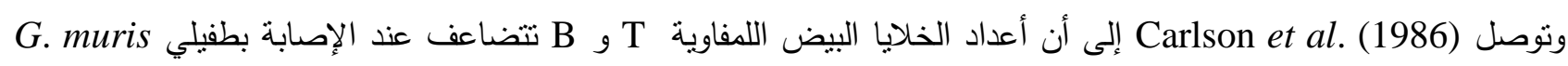

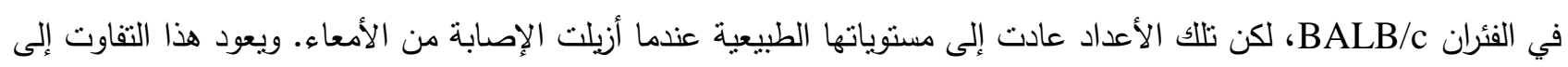
ارتباط أعداد الخلايا اللمفاوية بمدة الإصابة في الجرذان.

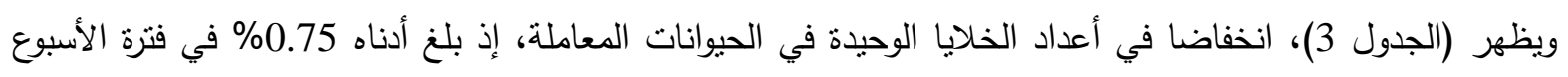

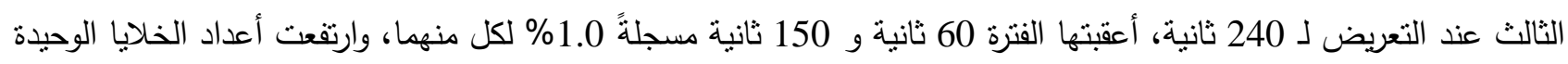
أيضاً في الفترة 210 ثانية خلال الأسابيع الثانية والثالثة والرابعة، وكذلك في الفترة 150 ثانية في الأسبوع الثاني فحسب وكانب وكانت الفروق غير معنوية بين مجاميع الحيوانات المعاملة ومجموعة السيطرة عند مستوى احتمالية (P>0.05). ويعزى ذلك الى تأثير الموجات فوق الصوتية في تحفيز هجرة الخلايا الوحيدة الى مواقع الإصابة بالطفيلي كونها من الخلايا

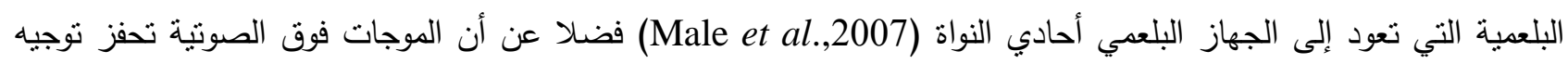

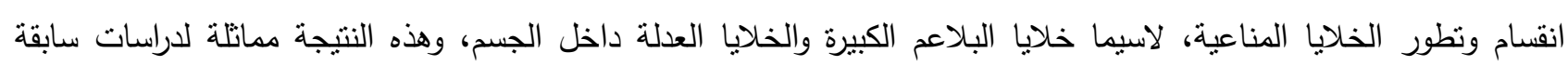
أجريت باستعمال التيار الكهربائي المباشر (Song et al., 2007; Cinar et al., 2009).

\section{اختبار فرط الحساسية المتأخر Delayed-type Hypersensitivity test (DHT)}

يوضح (الجدول 4) التغيرات الحاصلة في معدل سمك وسادة القدم في الجرذان المعاملة بالموجات فوق الصوتية

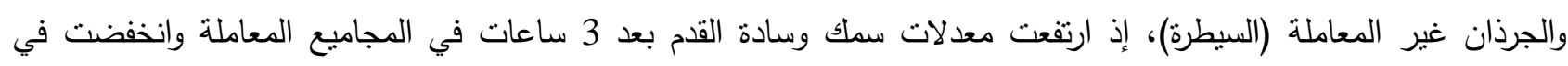

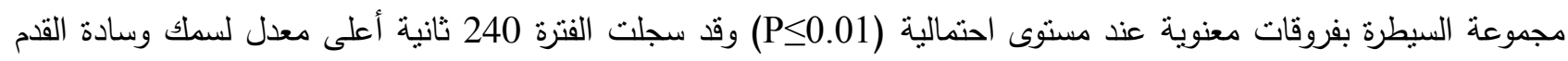
بلغ 1.75 ملم، ثم تلته الفترة 150 ثانية مسجلة سمكا قدره 1.325 ملم. وقد انخفضت تلفئ تلك المعدلات بعد 24 ساعة من الحقن في

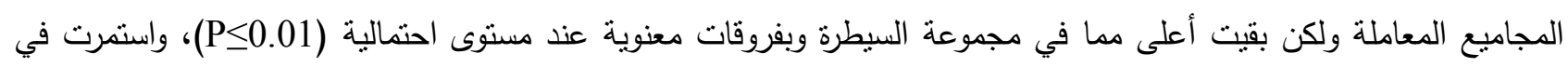
الانخفاض بعد 48 ساعة في المجاميع المعاملة مقارنة مع فترة 3 ساعات. 
الجدول رقم 3 : التغيرات الحاصلة في معدلات التعداد التفاضلي لخلايا الدم البيض غير الحبيبية (اللمفاوية ووحيدة النواة) في الجرذان المعاملة مقارنة بمجموعة السيطرة

\begin{tabular}{|c|c|c|c|c|c|c|}
\hline \multicolumn{4}{|c|}{ فترة التعريض ( ثانية ) } & \multirow{2}{*}{ السيطرة } & \multirow{3}{*}{ 离 } & \multirow{3}{*}{ الخلية } \\
\hline 240 & 210 & 150 & 60 & & & \\
\hline 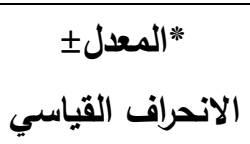 & "الانحراف & 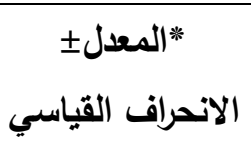 & 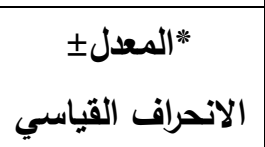 & $\begin{array}{c}\text { "المعدل الانحراف } \\
\text { القياسي }\end{array}$ & & \\
\hline $\begin{array}{c}81.25 \pm 10.436 \\
a-b\end{array}$ & $\begin{array}{c}74.25 \pm 3.40 \\
\text { a-c }\end{array}$ & $\begin{array}{c}76.0 \pm 3.651 \\
a-c\end{array}$ & $\begin{array}{c}75.25 \pm 5.56 \\
\mathrm{a}-\mathrm{c}\end{array}$ & $\begin{array}{c}60.0 \pm 18.293 \\
\mathrm{c}-\mathrm{d}\end{array}$ & অू & \multirow{4}{*}{ 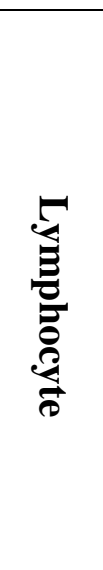 } \\
\hline $\begin{array}{c}79.25 \pm 13.257 \\
a-b\end{array}$ & $\begin{array}{c}70.75 \pm 7.67 \\
\text { a-d }\end{array}$ & $\begin{array}{c}65,75 \pm 22.58 \\
\text { b-d }\end{array}$ & $\begin{array}{c}67.25 \pm 10.9 \\
\text { b-d }\end{array}$ & $\begin{array}{c}64.5 \pm 12.87 \\
b-d\end{array}$ & 哥 & \\
\hline $\begin{array}{c}87.25 \pm 2.061 \\
\mathrm{a}\end{array}$ & $\begin{array}{c}87.0 \pm 6.976 \\
\mathrm{a}\end{array}$ & $\begin{array}{c}60.25 \pm 9.53 \\
c-d\end{array}$ & $\begin{array}{c}67.0 \pm 9.831 \\
\text { b-d }\end{array}$ & $\begin{array}{c}69.5 \pm 7.505 \\
\text { a-d }\end{array}$ & 牙 & \\
\hline $\begin{array}{c}80.0 \pm 6.976 \\
a-b\end{array}$ & $\begin{array}{c}80.5 \pm 5.802 \\
a-b\end{array}$ & $\begin{array}{c}78.75 \pm 7.135 \\
a-b\end{array}$ & $\begin{array}{c}53.5 \pm 11.618 \\
\mathrm{~d}\end{array}$ & $\begin{array}{c}59.5 \pm 17.82 \\
\text { c-d }\end{array}$ & $\overline{\overline{3}}$ & \\
\hline $\begin{array}{c}2.25 \pm 2.217 \\
a-b\end{array}$ & $\begin{array}{c}2.0 \pm 1.825 \\
a-b\end{array}$ & $\begin{array}{c}2.75 \pm 4.193 \\
a-b\end{array}$ & $\begin{array}{c}3.5 \pm 3.109 \\
\mathrm{~b}\end{array}$ & $\begin{array}{c}2.5 \pm 1.732 \\
a-b\end{array}$ & 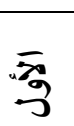 & \multirow{4}{*}{ 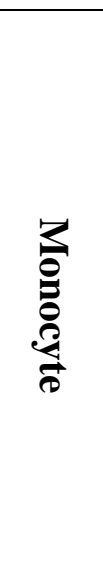 } \\
\hline $\begin{array}{c}1.5 \pm 1.732 \\
b\end{array}$ & $\begin{array}{c}4.25 \pm 4.349 \\
a-b\end{array}$ & $\begin{array}{c}6.0 \pm 4.69 \\
a\end{array}$ & $\begin{array}{c}2.5 \pm 1.914 \\
a-b\end{array}$ & $\begin{array}{c}2.5 \pm 2.061 \\
a-b\end{array}$ & 哥. & \\
\hline $\begin{array}{c}0.75 \pm 1.5 \\
b\end{array}$ & $\begin{array}{c}3.0 \pm 2.309 \\
\mathrm{a}-\mathrm{b}\end{array}$ & $\begin{array}{c}1.75 \pm 2.061 \\
\mathrm{a}-\mathrm{b}\end{array}$ & $\begin{array}{c}1.0 \pm 0.577 \\
b\end{array}$ & $\begin{array}{c}2.75 \pm 3.095 \\
a-b\end{array}$ & 牙 & \\
\hline $\begin{array}{c}1.5 \pm 2.38 \\
b\end{array}$ & $\begin{array}{c}2.75 \pm 3.403 \\
a-b\end{array}$ & $\begin{array}{c}1.0 \pm 0.0 \\
\mathrm{~b}\end{array}$ & $\begin{array}{c}1.0 \pm 0.816 \\
b\end{array}$ & $\begin{array}{c}1.75 \pm 2.217 \\
a-b\end{array}$ & $\overline{3}$ & \\
\hline
\end{tabular}

*يمتل المعدل لاربع مكررات 土 الانحراف القياسي. الحروف الإنكليزية المختلفة تدل على وجود فروقات معنوية اما الحروف الإنكليزية المتشابهة والمشتركة فتدل على عدم وجود فروقات معنوية بحسب اختبار دنكن عند مستوى احتمالية (P>0.01).

وتعزى هذه الزيادة إلى قدرة الموجات فوق الصوتية على حث المناعة الخلوية المتمثلة بالانتفاخ في وسادة القدم والذي

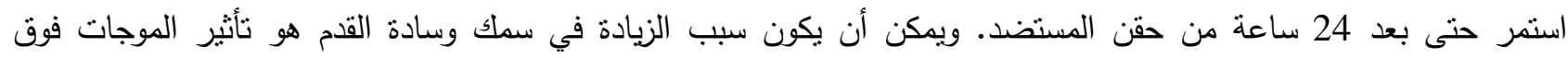
الصوتية على الخلايا البلعمية وتفعيلها الذي أدى بدوره إلى زيادة أعداد الخلايا اللدفاوية (Weiser et al., 1990)، وبالثالي حصول تتسيق بينهما وتتظيم حجم الاستجابة المناعية الخلوية، ويزيد من إفراز مركبات اللمف المنظمة للاستجابة المناعية (Male et al., 2007)، فضلا عن أن التحفيز بالموجات فوق الصوتية يعد معززاً لهجرة الخلية (Faurie et al., 2005). 
وجاءت هذه النتائج منطابقة مع دراسة باحثين آخرين لجأوا إلى استعمال التيار الكهربائي. فقد ذكروا أن الحقول

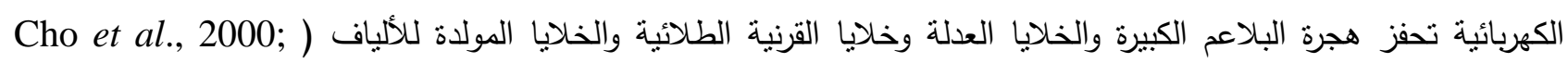
Gunja et al., 2011 (G) وقد تطابقت هذه النتائج مع دراسة Ahmad (2013) التي استعملت التيار الكهربائي المباشر ودرست وفئ تأثثره في المناعة الخلوية في الجرذان النرويجية المجرعة بأكياس الجيارديا المعرضة للتيار الكهربائي.

الجدول 4 : يبين التغيرات الحاصلة في معدلات سمك وسادة القدم (ملم) في الجرذان المعاملة مقارنة مع مجموعة السيطرة

\begin{tabular}{|c|c|c|c|c|c|}
\hline \multicolumn{4}{|c|}{ فترة التعريض ( ثانية ) } & \multirow{2}{*}{ 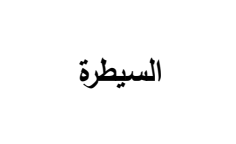 } & \multirow{3}{*}{ فترات القياس } \\
\hline 240 & 210 & 150 & 60 & & \\
\hline "المعدلـالانحراف & "القعدلـالانحراف & *المعدلذالانحراف القياسي & "المعدلـالانحراف & *المعدلـالانحراف & \\
\hline $\begin{array}{c}1.75 \pm 0.15 \\
\mathrm{a}\end{array}$ & $\begin{array}{c}1.025 \pm 0.129 \\
\text { a-d }\end{array}$ & $\begin{array}{c}1.325 \pm 0.282 \\
\mathrm{a}\end{array}$ & $\begin{array}{c}1.20 \pm 0 . \\
\text { a-c }\end{array}$ & $\begin{array}{c}0.225 \pm 0.05 \\
\mathrm{G}\end{array}$ & بعد 3 ساعات \\
\hline $\begin{array}{c}0.725 \pm 0.35 \\
\text { c-f }\end{array}$ & $\begin{array}{c}0.80 \pm 0.0 \\
\text { b-f }\end{array}$ & $\begin{array}{c}0.825 \pm 0.208 \\
\text { b-f }\end{array}$ & $\begin{array}{c}0.80 \pm 0.173 \\
\mathrm{c}-\mathrm{f}\end{array}$ & $\begin{array}{c}0.40 \pm 0.216 \\
\mathrm{f}-\mathrm{g}\end{array}$ & مد 24 ساعة \\
\hline $\begin{array}{c}0.725 \pm 0.12 \\
\text { c-f }\end{array}$ & $\begin{array}{c}0.575 \pm 0.05 \\
\text { e-g }\end{array}$ & $\begin{array}{c}0,475 \pm 0.206 \\
\text { e-g }\end{array}$ & $\begin{array}{c}0.50 \pm 0.17 \\
\mathrm{e}-\mathrm{g}\end{array}$ & $\begin{array}{c}0.375 \pm 0.408 \\
\mathrm{f}-\mathrm{g}\end{array}$ & لـ 48 ساعة \\
\hline
\end{tabular}

*يمثل المعدل لاربع مكررات 土 الانحراف القياسي. الحروف الإنكليزية المختلفة ندل على وجود فروقات معنوية اما الحروف الإنكليزية المتشابهة والمشتركة فتدل على عدم وجود فروقات معنوية بحسب اختبار دنكن عند مستوى احتمالية (P<0.01).

إن الصفة المميزة لتفاعلات فرط الحساسية هي نراكم الخلايا الحمضية في الأنسجة الذي يسبقه عملية تراكم الخلايا اللمفاوية المساعدة Bacillus Calmette Guerin (BCG) حيث تم استعمال لقاح T- helper cells TH مع مساعد فروند الكامل Complete Freund's Adjuvant أو مع بيوض المنشقات المانسونية Schistosoma mansoni في اختبار فرط الحساسية المنأخر في وسادة قدم الفئران، واتضح أن تفاعلات فرط الحساسية المتأخر تحفز إنتاج مواد كيميائية جاذبة وجزيئات

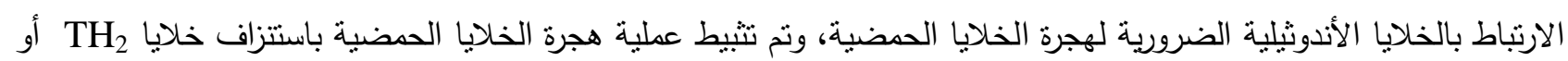

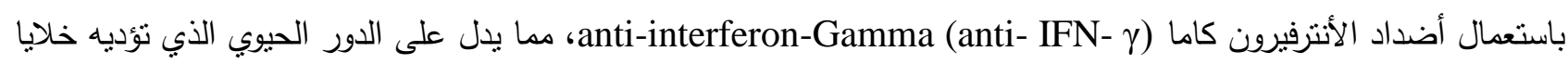
في تفاعلات فرط الحساسية المتأخر (Teixeira et al., 2001)، وقد تعزى الزيادة الحاصلة في سمك وسادة

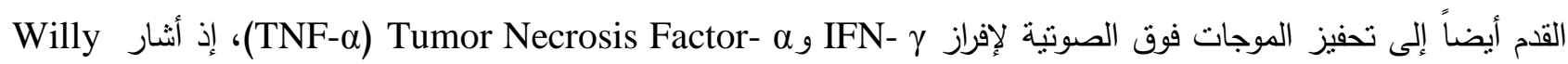

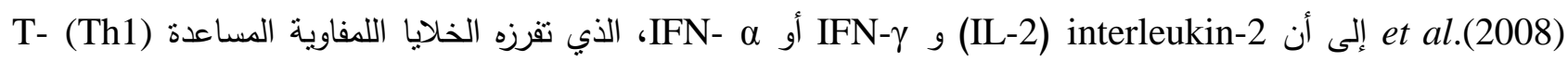
(helper cells الخلوية، وأن الورم يعود الى ارتشاح العدلات والبلاعم الكبيرة والخلايا الوحيدة والخلايا اللمفاوية عند الفحص النسجي لوسادة القدم

.(Ryu and Kim, 2000)

المصادر

Ahmad, S.S. (2013). Effect of direct electric current in immun response of Norvegicus rat Rattus norvigcus against infection with giardiasis. M.Sc. Thesis, Education College For Pure Sciences, University of Mosul, IRAQ . (In arabic). 
Al-Bataineh, O.; Jenne, J.; Huber, P. (2012). Clinical and future applications of high intensity focused ultrasound in Cancer. Treat Rev., 38(5), 346-353.

Ali Khan, Z. (1978). Echinococcus multilocularis: Cell mediated immune response in early and chronic alveolar murine hydatidosis. Exp. Parasitol., 46,157-165.

Al-Dabbag, F.A.; Rahemo, Z.F. (2010). Effect of gamma radiation on expermintal infection with giardia in white Norwegian rats. J.Edu.Sci., 23(2), 42-57. (In Arabic)

Ali Khan, Z. (1978). Echinococcus multilocularis: Cell mediated immune response in early and chronic alveolar murine hydatidosis. Exp. Parasitol., 46, 157-165.

Al-Sabi, M.N.S., Gad, J., Klinting, M., Mogensen, C., Kurtzhals, J.; Enemark, H.L.(2011). Effects of Ultrasound on the survival and characteristics of Cryptosporidium oocysts and Giardia cysts in GM Bulman (ed.), Procedings 32rd WAAVP 2011.

Aycan Kaya, M.A.; Atambay, M.; Yula, E.; Ozyalin, F.; Koksaldi, M.V.; Motor, S.; Celik, M.; Daldal, M. (2012). Assessment of the levels of nitric oxide (NO) in chronic diarrhea patients infected with Giardia intestinalis. African J. Microbiol. Res., 6(14), 3550-3553.

Beatty, J.; Bhargava, A.; Motta, J.; Feener, T.; McKnight, G.; Wallace, J.; Akierman, S.; Rioux, K.; Buret, A. (2014). Giardia duodenalis cysteine proteases modify human microbiota biofilms: a role in post-infectious epithelial dysfunction?. CDDW and the Annual CASL Winter Meeting. February 8-11, Tornto, Ontario .

Bingham, A.K.; Jarroll, E.I.; Meyer, E.A. (1979). Giardia Sp.: Physical factors of excystation in vitro and excystation vs eosin exclusion as determinants of viability. Exp. Parasitol., 47, 284-291.

Bhargava, A.; Ctton, J.; Amat, C.; Yates, R.; Buret, A. (2014). Giardia duodenalis Cathepsin-Like cysteine proteases disrupt human intestinalis villin, and MUC2 proteins. CDDW and the Annual CASL Winter Meeting. February 8-11, Tornto, Ontario

Buret, A.G. (2008). Pathophysiology of enteric infections with Giardia duodenalis. Parasitolgy, 15(3), 261-265.

Cacciò, S.M.; Ryan, U. (2008). Molecular epidemiology of giardiasis. Mol. Biochem. Parasitolo., 160,75-80.

Cai, H.; Chen, L.; Ye, B.; Liu, A.; Zhang, J.; Zhao, Y. (2013). The destructive effects of high intensity focused ultrasound on hydatid cysts enhanced by ultrasound contrast agent and superabsorbent polymer alone or in combination. Parasitol. Res., 112,707-717.

Carlson, J.R.; Heyworth, M.H.; Owen, R.L. (1986). Response of Peyer's patch lymphocyte subsets to Giardia muris infection in BALB/c mice. I. T-Cell subset. Cell Immunol., 97, 44-50.

Carmena, D. (2010). Waterborne transmission of Cryptosporidium and Giardia: detection, surveillance and implications for public health. Techenology and education topics in appelied microbiology and microbial biotechnology A. Mendz-vilas(Ed.) OFormatex.3-14.

Cheung, T.T.; Chu, F.S.; Jenkins, C.R.; Tsang, D.S.; Chok, K.S.; Chan, A.C.; Yau, T.C.; Chan, S.C.; Poon, R.T.P.; Lo, C.M.; Fan, S.T. (2012). Tolerance of high intensity focused ultrasound ablation in patients with hepatocellular carcinoma. World J. Surg., 36(10), 24202427.

Cho, M.R.; Thatte, H.S.; Lee, R.C.; Golon, D.E. (2000). Integrin-dependent human macrophage migration induced by oscillatory electrical stimulation. Ann. Biomed. Eng., 28, 234-243.

Cinar, K.; Comlekci, S.; Senol, N. (2009). Effects of a specially effects of a specially pulsed electric field on an animal model of wound healing. Lasers Med. Sci., 24,735-740.

Cotton, J.; Bhargava, A.; Ferraz, J.; Beck, P.; Buret, A. (2014). An assemblage a Giardia cathepsin b protease degrades interleukin- 8 and attenuates neutrophil chemotaxis. CDDW and the Annual CASL Winter Meeting. February 8-11, Tornto, Ontario.

Craft, J.C.; Nelson, J.D. (1982). Diagnosis of giardiasis by counter-immunoelectrophoresis of feces. J. Infect. Dis., 145(4), 499-504. 
Faubert, G. (2000). Immune response to Giardia duodenalis. Clin. Mircobiol Rev; 13: 35-54.

Faurie, C.; Golzio, E.P.; Teissie, J.; Rols, M.P. (2005). Electric field- induced cell membrane permeabilization and gene transfer: theory and experiments. Eng. Life Sci., 5:179-186.

Gerbaba, T.; Gupta, P.; Wang, X.; Rioux, K.; Hansen, D.; Buret, A.(2014). Giardia-induced alteration of microbiota and gut interactions: Caenorhabditis elegans as a model system. CDDW and the Annual CASL Winter Meeting. February 8-11, Tornto, Ontario.

Gomez, K.A.; Gomez, A.A. (1983)." Statistical Procedures for Agricultural Research". $2^{\text {nd }}$ ed., John Wiley and sons, New York.

Gunja, N.J.; Dujari, D.; Chen, A.; Luengo, A.; Fong, J.V.; Hung, C.T. (2011). Migration responses of outer and inner meniscus cells to applied direct current electric fields. J. Orthopaedic., 30, 103-111.

Heyworth, M.F.; Owen, R.L.; Seaman, W.E.; Schaefer, F.; Jones, A.L. (1985). Harvesting of leukocytes from intestinal lumen in murine giardiasis and preliminary characterization of these cells. Dig. Dis. Sci., 30, 149-153.

Inabo, H., Aminu, M., Muktar, H.; Adenran, Sh. (2012). Profile of intestinal parasitic infections associated with diarrhoea in HIV/AIDS patients in a Tertiary Hospital in Zaria, Nigeria. World J. Life Sci. Med. Res., 2(2),43.

Kamda J.D.; Nash Th.E.; Singer S.M.(2012). Giardia duodenalis: Dendritic cell defects in IL-6 deficient mice contribute to susceptibility to intestinal infection. Exp. Parasitol., 130, 288291.

Liu, A.; Cai, H.; Ye, B.; Chen, L.; Wang, M.; Zhang, J.; Zhao, Y.(2013). The damages of high intensity focused ultrasound to transplanted hydatid cysts in abdominal cavities of rabbits with aid of ultrasound contrast agent and superabsorbent polymer. Parasitol. Res., 112, $1865-1875$.

Male, D., Brostoff, J., Roth, D.; Roitt, I. (2007). "Immunology". $7^{\text {th }}$ ed. Inter. Edith Mosby Elsevier Ltd. U.K.

Monis, P.T.; Cacciò, S.M.; Thompson, R.C. (2009). Variation in Giardia: Towards a taxonomic revision of the genus. Trends in Parasitology. 25, 93-100.

National Institute For Health and Clinical Excellence Interventional Procedure Guidance 424(NICE) (2012). Focal therapy using high-intensity focused ultrasound for localised prostate cancer. Nice .Org. UK. Guidance. IPG 424.

Omarova, A.; Tussupova, K.; Berndtsson, R.; Kalishev, M.; Sharapatova, K.(2018). Protozoan parasites in drinking water: A system approach for improved water, sanitation and hygiene in developing countries. Int. J. Environ. Res. Public Health, 15,495.

Poorsaadat, L.; Jamshidifard, A.R.; Davami, M.H. (2004). Effect of direct electric current on water infected with Giardia lamblia. J. med. Res. (JMR)., 3(1),65-70.

Ringqvista, E.; Avesson, L.; Söderbom, F.; Svard, S.G. (2011). Transcriptional changes in Giardia during host-parasite. Interactions. Int. J. Parasitol., 41, 277-285.

Roberts-Thomson, I.C.; Stevens, D.P.; Mahmoud, A.A.F.; Warren, K.S. (1976). Giardiasis in the mouse: an animal model. Gastroenterology, 71, 57-61.

Ryu, H.; Kim, C. (2000). Immunologic reactivity of a lipopolysaccharide-protein complex of type A Pasteurella multocida in mice. J. Vet. Sci., 1 (2), 87-95.

Samn, K.A.M.; Samn, A.A.M.; Abou El-Nour, M.F. (2012). A survey of Giardia and Cryptosporidium spp. in rural and urban community in North Delta, Egypt. New York Science J., 5(3),49-54.

Scott, K.G.; Yu, C.H.; Buret, A.G. (2004). Role of CD8+ and CD4+ T lymphocytes in jejunal mucosal injury during murine giardiasis. Infect. Immun., 72, 3536-3542.

Schacterle, G.R.; Pollack, R.L. (1973). A simplified method for the quantitative assay of small amount of protein in biologic materials. Anal. Biochem., 51, 654-655. 
Shnawa, B.H. (1995). Biological and immunological studies on Giardia lamblia. Ph.D. Thesis, Univ. Basrah. (In Arabic)

Shukla, G.; Sharma, G.; Goyal, N. (2010). Probiotic characterization of Lactobacilli and yeast strains isolated from whey beverage and therapeutic potential of Lactobacillus yoghurt in murine giardiasis. Am. J. Biomed. Sci., 2, 248-261.

Simpson, K.W.; Rishniw, M.; Bellosa, M.; Liotta, J.; Lucio, A.; Baumgart, M.; Czarnecki-Maulden, G., Benyacoub, J.; Bowman, D. (2009). Influence of Enterococcus faecium SF68 probiotic on giardiasis in dogs. J. Vet. Inter. Med.10, 1-6.

Song, B.; Gu, Y.; Pu, J.; Reid, B.; Zhao, Z.; Zhao, M. (2007). Application of direct current electric fields to cells and tissues in vitro and modulation of wound electric field in vivo. Nature protocols. 2(6),1479-1489.

Teixeira, M.M.; Talvani, A.; Tafuri, W.L.; Lukacs, N.W.; Hellewell, P.G. (2001). Eosinophil recruitment into sites of delayed-type hypersensitivity reactions in mice . J. Leukoc. Biol., 69, 353-360.

Turki, N.M.; Mallah, M.O.; Kremsh, Y.D.( 2015). Iraqi genotyping of Giardia lamblia ( A, B, E, F) in human stool in Al- Muthanna Province. Int. J. Adv. Res.,3(10), 757-771.

Vinayak, V.K.; Khanna, R.; Kum, K. (1991). Kinetics of intraepithelium and lamina propria lymphocyte responses during Giardia lamblia infection in mice. Microb. Pathog., 10, 343350 .

Wang, W.; Wang, Y.; Wang, T.; Wang, J.; Wang, L.; Tang, J.(2012). Safety and efficacy of usguided high intensity focused ultrasound for treatment of submucosal fibroids. Eur. Radiol., 22(11), 2553-2558.

Waynforth, H.B. (1980). "Experimental and Surgical Technique in the Rat ". Academic Press Inc., (London) LTD , NWI, 29p.

Weiser, W.Y., Pozzi, L.A.; David, J.R. (1990). Human recombinant migration inhibition factor activates human macrophages to kill Leishmania donovani. J. Immnunol.,174, 2006-2011.

Willey, J.M.; Sherwood, L.M.; Woolverton, C.J. (2008). "Prescott, Harley and Klein's Microbiology". $7^{\text {th }}$ ed., McGraw-Hill Companies, Inc., USA, pp.782-788.

Yousaf, M.; Jan, S.; Shafee, M.; Samad, A.; Barkhurdar, M.; Bugti, F.S.; Tariq, T.; Roomeela, S.; Saifullah, S.; Akhtar, W.; Ahmed, S.(2018). Prevalence of Giardia lamblia in stool samples of diarrhea patients in Quetta, Pakistan.

Zhang, J.; Ye, B.; Kong, J.; Cai, H.; Zhao, Y.; Han, X.; Li, F. (2013). In vitro protoscolicidal effects of high intensity focused ultrasound enhanced by superabsorbent polymer. Parasitol. Res., 112,385-391.

Zhang, Q.; Xiang, T.J.G.; Wo Chan, W.P.(2016). A patient with Typhoid fever, Giardia lamblia gastroenteritis and hepatitis E. Proceedings of Singapore Healthcare, 25(1), 61-63. 